Volume 8

Issue 4 - Cancer Screening

Article 5

10-18-2021

\title{
Increasing Breast, Cervical, and Colorectal Cancer Screenings: A Qualitative Assessment of Barriers and Promoters in Safety-Net Practices
}

\author{
Laura A. Brady \\ Laurene M. Tumiel-Berhalter \\ Laura A. Schad \\ Alexandrea Bentham \\ Karen Vitale \\ Amanda Norton \\ Gary Noronha \\ Carlos Swanger \\ Christopher P. Morley
}

Follow this and additional works at: https://aah.org/jpcrr

Part of the Community Health and Preventive Medicine Commons, Family Medicine Commons, Internal Medicine Commons, Preventive Medicine Commons, and the Quality Improvement Commons

\section{Recommended Citation}

Brady LA, Tumiel-Berhalter LM, Schad LA, Bentham A, Vitale K, Norton A, Noronha G, Swanger C, Morley CP. Increasing breast, cervical, and colorectal cancer screenings: a qualitative assessment of barriers and promoters in safety-net practices. J Patient Cent Res Rev. 2021;8:323-30. doi: 10.17294/2330-0698.1857

Published quarterly by Midwest-based health system Advocate Aurora Health and indexed in PubMed Central, the Journal of Patient-Centered Research and Reviews (JPCRR) is an open access, peer-reviewed medical journal focused on disseminating scholarly works devoted to improving patient-centered care practices, health outcomes, and the patient experience. 


\title{
Increasing Breast, Cervical, and Colorectal Cancer Screenings: A Qualitative Assessment of Barriers and Promoters in Safety-Net Practices
}

\author{
Laura A. Brady, PhD, ${ }^{1}$ Laurene M. Tumiel-Berhalter, PhD,,${ }^{1,2}$ Laura A. Schad, MPH, ${ }^{3}$ Alexandrea \\ Bentham, BS, ${ }^{1}$ Karen Vitale, MSEd,${ }^{4}$ Amanda Norton, MSW, ${ }^{5}$ Gary Noronha, MD,${ }^{6}$ Carlos Swanger, \\ $\mathrm{MD}, 6,7$ Christopher P. Morley, PhD, MA ${ }^{3}$ \\ ${ }^{1}$ Department of Family Medicine, State University of New York (SUNY) University at Buffalo, Buffalo, NY; ${ }^{2}$ University \\ at Buffalo Clinical and Translational Science Institute, Buffalo, NY; ${ }^{3}$ Department of Public Health and Preventive \\ Medicine, SUNY Upstate Medical University, Syracuse, NY; ${ }^{4}$ University of Rochester Clinical and Translational \\ Science Institute, Rochester NY; ${ }^{5}$ A. Mandatory, Inc. (consulting for SUNY Upstate Medical University), Groton, NY; \\ ${ }^{6}$ Center for Primary Care, Department of Medicine, University of Rochester School of Medicine and Dentistry, \\ Rochester, NY; ${ }^{7}$ Health Reach for the Homeless, Rochester Regional Health, Rochester, NY
}
Purpose Breast, cervical, and colorectal cancer screening rates are suboptimal in underserved populations. A 7-year quality improvement (QI) project implemented academic detailing and practice facilitation in safety-net primary care practices to increase cancer screening rates. This manuscript assesses barriers and promoters.

Methods Primary care practices providing care to underserved patients were recruited in New York cities Buffalo, Rochester, and Syracuse. Enrollment totaled 31 practices, with 12 practices participating throughout. Annually, each practice received 6 months of practice facilitation support for development and implementation of evidence-based interventions to increase screening rates for the three cancer types. At the end of each practice facilitation period, focus groups and key informant interviews were conducted with participating personnel. Content analysis was performed annually to identify barriers and promoters. A comprehensive final analysis was performed at project end.

Results Barriers included system-level (inconsistent communication with specialists, electronic health record system transitions, ownership changes) and practice-level challenges (staff turnover, inconsistent data entry, QI fatigue) that compound patient-level challenges of transportation, cost, and health literacy. Cyclical barriers like staff turnover returned despite attempts to resolve them, while successful implementation was promoted by reducing patients' structural barriers, adapting interventions to existing practice priorities, and enacting officewide policies. During the QI project, practices became aware of the impact of social determinants of health on patients' screening decisions.

Conclusions The project's longitudinal design enabled identification of key barriers that reduced accuracy of practices' screening rates and increased risk of patients falling through the cracks. Identified promoters can help sustain interventions to increase screenings. (J Patient Cent Res Rev. 2021;8:323-330.)

Keywords cancer screening; quality improvement; breast cancer; cervical cancer; colorectal cancer

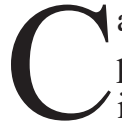
ancer screening rates are lower for underserved populations than for the general U.S. population, including among minority, rural, and foreign-born communities. ${ }^{1,2}$ As regular screenings help to detect new cancers, such disparities in screening rates are directly related to higher cancer morbidity and mortality rates

Corresponding author: Christopher P. Morley, Department of Public Health and Preventive Medicine, Upstate Medical University, 750 E. Adams St., Weiskotten Hall 2262, Syracuse, NY 13210 (MorleyCP@upstate.edu) among underserved populations. ${ }^{3,4}$ While non-Hispanic Caucasians have the highest overall incidence of cancer in the United States, non-Hispanic African Americans have the highest mortality rates. ${ }^{4}$ Access to care plays a large role in these rates, but other barriers can remain when primary care is available. ${ }^{2}$ While safety-net practices provide care for Medicaid, underinsured, and uninsured patients, patients still experience barriers to care around transportation, cost, health literacy, language, and cultural differences ${ }^{5,6}$ Further, safety-net practices often have limited resources, affecting their ability to educate and support patients, while the fragmented nature of the 
parent health system complicates their ability to track screening outcomes. Such barriers at all levels negatively impact underserved patients, and disparities in cancer screening rates reflect this reality. ${ }^{7,8}$

This grant-funded longitudinal quality improvement (QI) project was a partnership between the State University of New York (SUNY) Upstate Medical University, SUNY University at Buffalo, University of Rochester Medical Center, and their local practice-based research networks located in western and central New York State. Aims of the 7-year QI project included: 1) increase breast, cervical, and colorectal cancer screening rates within the safetynet primary care practices; and 2) assess barriers to and promoters of evidence-based intervention success during the project. ${ }^{9}$ The project's ultimate goal was to benefit underserved patients and communities, as increased screening leads to reductions in cancer screening disparities, incidences of new cancers, and preventable deaths.

To meet Aim 1, the combined intervention of academic detailing ${ }^{10,11}$ and practice facilitation $(\mathrm{PF})^{12,13}$ was implemented at safety-net primary care practices in Buffalo, Rochester, and Syracuse to support translation of evidence-based best practices into clinic processes. To meet Aim 2, annual focus groups and key informant interviews were conducted with practice staff at the end of project years 1 through 6 (ie, Y1-Y6) to discuss their experiences with the project, including what strategies the practices were implementing with the assistance of their practice facilitator and any barriers to and promoters of their attempts to increase cancer screening rates. Project outcomes were assessed annually by a multimethod/ multiphase evaluation, and the results were summarized in project reports. ${ }^{9}$ The results of Aim 2 form the basis of this manuscript, whereas the QI project's impact on longitudinal screening rates and effect of COVID-19 on participating practices in $\mathrm{Y} 7$ are described in more detail elsewhere in this issue of Journal of Patient-Centered Research and Reviews. ${ }^{14,15}$

As we report herein, several barriers and promoters of increased cancer screenings experienced by the New York safety-net practices mirror those reported in other areas of the United States, from challenges related to patients' social determinants of health $(\mathrm{SDoH})$ to the benefits of implementing multiple evidence-based interventions. ${ }^{5,8,16,17} \mathrm{We}$ attempt to build on this literature by identifying further barriers and promoters that arose over 7 years of QI implementation, from ownership and electronic health record (EHR) transitions to ransomware attacks. Findings highlight the cyclical nature of certain

Table 1. Main Evidence-Based Intervention Strategies That Practice Facilitators Assisted Practices in Implementing or Updating

\begin{tabular}{l|l|l}
\hline $\begin{array}{l}\text { Evidence-based } \\
\text { intervention }\end{array}$ & Description & Examples of practice implementation \\
\hline Client reminders & $\begin{array}{l}\text { Messages advising } \\
\text { patients that they are } \\
\text { due for screening }\end{array}$ & $\begin{array}{l}\text { - Letters } \\
\text { - Telephone calls } \\
\text { - Text messages }\end{array}$ \\
\hline Small media & $\begin{array}{l}\text { Resources to inform } \\
\text { and motivate patients } \\
\text { to be screened }\end{array}$ & $\begin{array}{l}\text { - Slideshows on digital frames in exam rooms } \\
\text { - Brochures/pamphlets in the waiting room } \\
\text { - Posters }\end{array}$ \\
\hline One-on-one education & $\begin{array}{l}\text { Delivery of information } \\
\text { to patients about } \\
\text { indications for, benefits } \\
\text { of, and ways to } \\
\text { overcome barriers to } \\
\text { cancer screening }\end{array}$ & $\begin{array}{l}\text { - Provider-led } \\
\text { - Nurse-led } \\
\text { - Usually combined with small media for education on indications } \\
\text { and benefits } \\
\text { - Where available, patient navigators or care managers educated } \\
\text { patients on ways to overcome barriers }\end{array}$ \\
\hline $\begin{array}{l}\text { Reducing structural } \\
\text { barriers }\end{array}$ & $\begin{array}{l}\text { Reduction of } \\
\text { noneconomic barriers } \\
\text { that make it difficult } \\
\text { for patients to access } \\
\text { screening (eg, language, } \\
\text { transportation, patient } \\
\text { navigation) }\end{array}$ & $\begin{array}{l}\text { - Distributing FIT kits during patient visits } \\
\text { - Distributing FIT kits by mail to patients who successfully completed } \\
\text { one previously } \\
\text { - Mobile mammography bus days at the primary care practice } \\
\text { - Translate reminders and small media into patient's primary language } \\
\text { - Front desk staff assist patients with scheduling appointments for } \\
\text { specialty providers such as gastroenterologists and gynecologists }\end{array}$ \\
\hline
\end{tabular}

aIntervention strategies were selected based on the CDC's Community Guide to Preventive Services.

CDC, Centers for Disease Control and Prevention; FIT, fecal immunochemical test. 
barriers that continue to impact low-resource practices despite targeted interventions and identify a shift from practice staff's perception of patients as noncompliant to an emphasis on how SDoH impact patients' screening decisions. We hope these key results will serve to illustrate why underserved patients continue to fall through the cracks and demonstrate successful strategies that safetynet practices can implement to increase preventive screenings for eligible patients.

\section{METHODS}

\section{Recruitment and Implementation}

After SUNY Upstate Medical University's institutional review board determined this project to be quality improvement, clinical sites were recruited based on their relationship with a participating practice-based research network and care for underserved populations such as minority, rural, Medicaid-eligible, and uninsured patients. Practices received a small stipend to assist with implementation costs. Enrollment totaled 31 practices; however, only 12 practices chose to participate for the duration of the project. Practice types included physicianowned, nonprofit, university/hospital-affiliated, Federally Qualified Health Center, and member of a larger medical group or health system. Several practices joined larger groups or systems during the course of the 7-year project.

At project start, practices received a 1-hour academic detailing session on updated breast, cervical, and colorectal cancer screening guidelines and evidencebased strategies to increase screening rates among eligible patient populations. An online version was shared with continuing practices. Practices also received annual PF services. Y1 focused on colorectal cancer, with a 2-month PF period. Y2 through Y7 included breast, cervical, and colorectal cancer, with 6-month PF periods. While the QI intervention was academic detailing with $\mathrm{PF}$, the practice facilitators guided practices in implementing evidencebased, practice-level strategies to increase cancer screening rates. Examples are shown in Table 1.

\section{Analysis}

From Y1 to Y6, focus groups and key informant interviews were conducted annually after completion of the PF period in order to identify and assess barriers to and promoters of increasing screening rates (Table 2). Y7 processes differed due to planned close-out procedures and the unplanned COVID-19 pandemic. $^{15}$ The same structured guide, which included questions on intervention activities, future prevention plans, staff and PF roles, and feedback on the project, was used for focus groups and interviews; barriers to sustainability were added for Y6. Specifics of the question guide are available in Online Supplemental Table S1.
Table 2. Number of Focus Groups and Key Informant Interviews by Project Year

\begin{tabular}{lccc}
\hline Project year & $\begin{array}{c}\text { Participating } \\
\text { practices }\end{array}$ & $\begin{array}{c}\text { Focus } \\
\text { groups }\end{array}$ & $\begin{array}{c}\text { Key } \\
\text { informant } \\
\text { interviews }\end{array}$ \\
\hline Year 1 & 9 & 8 & 1 \\
Year 2 & $23^{\mathrm{a}}$ & 3 & 20 \\
Year 3 & 13 & 6 & 7 \\
Year 4 & 13 & 8 & 5 \\
Year 5 & $13^{\mathrm{b}}$ & 5 & 6 \\
Year 6 & $12^{\mathrm{b}}$ & 5 & 5 \\
\hline
\end{tabular}

${ }^{a}$ After piloting the academic detailing and practice facilitation intervention for colorectal cancer in year 1 , the quality improvement project expanded to include breast and cervical cancer starting with year 2 . Recruitment increased, leading to a jump in the number of participating practices. However, not all practices continued to participate for the duration of the project. Main reasons given for not continuing were competing demands and organizational barriers.

${ }^{b}$ In year 5 and year 6 , two practices in Buffalo were jointly managed by one practice manager, and two practices in Rochester were jointly managed by another practice manager. Each year, managers were interviewed once and asked about the specifics of both of their practices.

When a practice could not schedule a focus group, key informant interviews were conducted with the practice's point person for the QI project. Usually the practice manager, QI specialist, or clinical champion, they were selected for their first-hand experience working with the practice facilitator to increase screening rates. Focus groups included the point person and other personnel who worked to implement the practice-level strategies, such as nurses, physicians, and care coordinators. The practice's assigned facilitator was excluded to reduce bias in responses.

Focus groups and interviews were conducted in person at the practices or by telephone; all sessions were audiorecorded, transcribed, and de-identified. Subsequently, a thematic content analysis was performed by a qualified team member. Each year, the transcripts were reviewed and a code list was developed, after which each transcript was open coded. The codes were then organized by topic area, and items coded as barriers or promoters were categorized by level (patient, practice, or system). Results were summarized and reviewed by the larger project team. At the conclusion of the project, the first author (L.A.B.), an anthropologist, conducted a comprehensive final analysis of Y1-Y6. Topic areas and summaries for each year were selectively coded and reviewed for longitudinal trends. Results were then checked against the original transcripts for accuracy and reviewed by the larger team. 


\section{RESULTS}

Analysis revealed new barriers and promoters that practices experienced during their PF-guided implementation of strategies to increase cancer screening rates. These occurred at the health system, practice, and patient levels. Quotations illustrating barriers and promoters at each level are shown in Table 3.

\section{System Level}

Common barriers experienced at the health system level included difficulty in two-way communication with specialists, practice ownership transitions, EHR system transitions, and ransomware attacks. As others have shown, closing the loop with specialists is a barrier for many primary care practices. ${ }^{18}$ Practices in this project discussed how inconsistent communication with gastroenterologists and gynecologists reduced the accuracy of their screening rates.

Ownership transitions were a new barrier identified over the 7-year project. Several practices changed from physician-owned or university/hospital-affiliated to practices within larger medical groups or health systems. The resulting shifts in policies and metrics frequently complicated or even terminated ongoing interventions.

A related barrier was EHR transitions, which often accompanied changes in ownership. Transitioning from one EHR system to another created multiple obstacles to increasing screening rates, from the time needed for staff trainings to disruptions in the eligible patient registries used to target patient outreach and education. A last barrier was unique to two practices affiliated with the same hospital. During Y4, a ransomware attack shut down the hospital's EHR access, including for the two practices in this project, and prevented them from calculating their screening rates.

Similar to other cancer screening research, the main system-level promoters experienced by participating practices were larger initiatives to improve patient care. ${ }^{8}$ These included team-based care and patient-centered medical home certification requirements.

\section{Practice Level}

The main barriers experienced at the practice level matched those reported in the literature, including workflow inefficiencies, inconsistent EHR data entry, staff turnover, and differing levels of engagement with QI initiatives. ${ }^{13}$ While practice facilitators assisted practices in improving workflow inefficiencies, inconsistent EHR data entry and personnel turnover were barriers that arose repeatedly during the 7-year project despite the work of facilitators and practices to address them.
Inconsistent EHR data entry was a particular challenge, as it impacted management of both individual patients and population health. Staff turnover repeatedly slowed implementation of evidence-based strategies, as did differing levels of QI engagement. Few practices had dedicated QI personnel, so interventions were initiated by clinical champions and practice managers with competing responsibilities who frequently reported struggling to involve staff.

Practice-level promoters of increased cancer screening rates addressed these barriers in several ways. QI coaching and workflow assessment and adjustment were two strategies that helped practices efficiently utilize their limited personnel. To overcome inconsistencies in the practice EHR, standardization of data entry and technical assistance were important. A focus on team-based care also was important, and point-of-care reminders - either through highlighting and flagging a patient's paper record or through EHR notifications - prompted care teams to discuss screening options with an eligible patient.

Finally, a key promoter over the 7-year project was the practices' utilization of health information systems to update their EHR. Practice staff developed workflows to search payer data and regional health information systems, such as HEALTHeLINK in western New York, for patient screening results to update their internal EHR records. This workaround increased the accuracy of patient registries.

\section{Patient Level}

Focus group and interview participants, i.e., all providers and practice staff, discussed their perceptions of patient barriers. Their statements over 7 years revealed a crucial shift in attitudes. In the early years of the project, the practices emphasized patient noncompliance and refusal as barriers to cancer screening. In more recent years, participants shifted their focus to $\mathrm{SDoH}$ and other barriers to care that patients may face when making a screening decision.

This included cultural and linguistic barriers, which practices can experience in their work with minority, migrant, and refugee populations. ${ }^{2,5}$ Colorectal cancer screenings, in particular, can clash with cultural beliefs, while a lack of female providers can be a barrier to Pap smears and human papillomavirus testing. Health literacy also was discussed as an important barrier, with patients not aware of how important preventive care is to their health. ${ }^{1}$ In later years, many participants connected this lower health literacy to SDoH, noting that it wasn't only that patients did not see the value of asymptomatic screening but that they had competing demands. Practices consistently recognized some patient-level barriers 
Table 3. Perspectives on Promoters of and Barriers to Intervention Success From Safety-Net Practice Personnel

\begin{tabular}{|c|c|c|c|}
\hline Level & Theme & $\begin{array}{l}\text { Promoter } \\
\text { or barrier }\end{array}$ & Selected quotation \\
\hline \multirow[t]{2}{*}{$\begin{array}{l}\text { System } \\
\text { level }\end{array}$} & $\begin{array}{l}\text { Closing the } \\
\text { loop }\end{array}$ & Barrier & $\begin{array}{l}\text { One of the other barriers is sharing the data and information. So, having that } \\
\text { feedback from outside referrals sources, or a patient that says, 'Well I went and had } \\
\text { my pap smear done here.' Or 'I had colonoscopy done } 10 \text { years ago,' and then you } \\
\text { can't get the information that you need. You know, to have it in the chart because } \\
\text { documentation is the key. And so that's hard because you are doing a lot of chasing } \\
\text { on paper. } \\
\text { - FQHC, Y3 }\end{array}$ \\
\hline & $\begin{array}{l}\text { Initiatives to } \\
\text { improve } \\
\text { patient care }\end{array}$ & Promoter & $\begin{array}{r}\text { [The nurses] go through the pre-planning that I give to them- they keep those at their } \\
\text { desk and they do go over those with the providers as best as possible in a huddle in } \\
\text { the morning if they are able to catch them before they start seeing patients. } \\
\text { - University Hospital/Clinic, Y5 }\end{array}$ \\
\hline \multirow[t]{4}{*}{$\begin{array}{l}\text { Practice } \\
\text { level }\end{array}$} & $\begin{array}{l}\text { Inconsistent } \\
\text { EHR data entry }\end{array}$ & Barrier & $\begin{array}{l}\text { The big thing for us has been it's hard to know how much work you need to do or how } \\
\text { much outreach you are still needing when you don't know what your real numbers are. } \\
- \text { FQHC, Y1 }\end{array}$ \\
\hline & $\begin{array}{l}\text { Low } \\
\text { engagement } \\
\text { in Q। } \\
\text { interventions }\end{array}$ & Barrier & $\begin{array}{l}\text { I think it's one of those things that 'Of course I care about quality,' but then when } \\
\text { they get into their day-to-day it turns into 'I don't have time for that.' }\end{array}$ \\
\hline & $\begin{array}{l}\text { Team-based } \\
\text { care }\end{array}$ & Promoter & $\begin{array}{l}\text { It wasn't always just about the provider. I mean the provider can do it when they're } \\
\text { seeing the patient, encouraging them to get it, why it's important, how it's done and } \\
\text { all of that. But it also comes down to the whole staff. I think medicine has moved in } \\
\text { this direction. It's not about any one individual, it's us as a group. } \\
- \text { Large Medical Group/Health System, Y4 }\end{array}$ \\
\hline & $\begin{array}{l}\text { Health } \\
\text { information } \\
\text { systems } \\
\text { workaround }\end{array}$ & Promoter & $\begin{array}{l}\text { I spent about } \$ 3,000 \text { this summer just paying people to do [records cleaning] outside } \\
\text { of the normal work hours. I would never have been able to get that done because } \\
\text { I'm sure like you hear there is never enough time to do everything. } \\
\text { - Large Medical Group/Health System, Y5 }\end{array}$ \\
\hline \multirow[t]{3}{*}{$\begin{array}{l}\text { Patient } \\
\text { level }\end{array}$} & $\begin{array}{l}\text { Patient } \\
\text { noncompliance }\end{array}$ & Barrier & $\begin{array}{r}\text { You have that large quantity of patients that you can continue to talk to until you are } \\
\text { blue in the face, and some just straight out refuse. Or, 'oh yeah, we'll get around to it.' } \\
- \text { Physician-Owned, Y2 }\end{array}$ \\
\hline & $\begin{array}{l}\text { Social } \\
\text { determinants } \\
\text { of health }\end{array}$ & Barrier & $\begin{array}{l}\text { There is a lot of social determinant of health issues such as food insecurity, } \\
\text { transportation and literacy problems. Patients sometimes have other priorities that } \\
\text { they would rather take care of than get a mammo done. It's not something that } \\
\text { they're going to be worried about, especially if they are not having issues. } \\
\text { - University Hospital/Clinic, Y6 }\end{array}$ \\
\hline & $\begin{array}{l}\text { Trusting } \\
\text { relationship } \\
\text { between } \\
\text { provider/staff } \\
\text { and patient }\end{array}$ & Promoter & $\begin{array}{l}\text { This year, with a new provider it was getting that comfort level built. They have to have } \\
\text { a good relationship with the provider and trust the provider to be able to go in. A lot of } \\
\text { them don't want to go in for a colonoscopy or don't want to go in and have a pap when } \\
\text { it's somebody new. It's really been a lot of just working with them and meeting the } \\
\text { provider and the provider educating them on all of these things and why they're doing it. } \\
- \text { FQHC, Y6 }\end{array}$ \\
\hline
\end{tabular}

EHR, electronic health record; FQHC, Federally Qualified Health Center; QI, quality improvement; Y, project year.

throughout the project, such as financial constraints and challenges with transportation, insufficient insurance coverage, and high deductibles.

The main promoters at the patient level counteracted these barriers and matched those reported in the literature; strategies focused on increasing patient access to care and understanding of cancer prevention. ${ }^{5,8}$ From Y1, patient education and outreach were important promoters, as was the reduction of structural barriers - especially transportation. A key example is access to mobile mammography units, which enable patients to be screened for breast cancer at their primary care clinic. A similar promoter is lifestyle-amenable screening methods that better fit the needs of different populations. One participating practice provided care to people with housing insecurity. They sent reminder texts since calls require minutes, and staff picked up completed fecal immunochemical test (FIT) kits from shelters.

A final promoter that emerged in the last years of the project is a trusting relationship between patients and 
their providers and staff. Several participants discussed relationships as a key factor involved in the success of patient outreach and care management. One practice director highlighted the longstanding relationship between one of her front desk staff and their patients, describing how outreach and reminder calls were a success because the staff member knew the patients' individual life histories and barriers.

\section{DISCUSSION}

The longitudinal nature of this 7-year project enabled the identification of a range of barriers experienced by safetynet practices during QI interventions to increase cancer screening rates, including trends in the health care industry and cyclical barriers. A prime example of a growing trend is the changes that occurred in practice ownership, with physician-owned, nonprofit, and university- or hospitalaffiliated clinics joining large health systems and medical groups. The ransomware attack on a local hospital is another example. Though it was a singular event, cyberattacks are occurring more frequently and warrant awareness of their potential impact on patient care. ${ }^{16}$

Several barriers to increasing cancer screening rates were resolved with $\mathrm{PF}$, including workflow inefficiencies and patient transportation. Others were cyclical, repeatedly challenging practices despite targeted strategies to address them. It is these barriers that require sustained attention and resources to overcome. Two such barriers are inconsistent EHR data entry and inconsistent communication between primary care providers and specialists. While practices implemented strategies to reduce these barriers, they could not prevent the barriers from reoccurring. This led many practices to describe their screening rates as less than accurate, since both barriers reduced the practices' ability to track patient cancer screenings. Staff turnover was another key barrier. A practice that treated people experiencing homelessness reported fewer cervical cancer screenings while in the process of replacing their female provider. Many of the women they served had experienced trauma and having a female provider available was important for their screenings.

Finally, the impact of SDoH was another key barrier. The term includes a number of challenges for patients, from lack of insurance or transportation to being unable to take time off from work. These barriers presented a particular problem for colonoscopies, with the need for transportation and an accompanying adult during the workday. In addition, a certain level of health literacy facilitated proper completion of the colonoscopy prep, especially for patients with comorbidities like diabetes. The practices' growing awareness of SDoH over the 7-year project parallels a growing awareness in health services of how a patient's social environment impacts care. ${ }^{17,20,21}$

The longitudinal design helped in identifying 3 key promoters for increasing cancer screening rates. These promoters represent the more general critical components behind the success of the more specific promoters identified in the results (Table 4). The first is sharing best practices across sites. Practice facilitators often shared early adopters' successful interventions with other participating practices. Knowing that a strategy succeeded for a similar practice encouraged other practices to implement it. The best examples of this were the uptake of mobile mammography and FIT kits. In Y1, only 1 participating practice utilized FIT testing as an alternate to colonoscopy for eligible patients. By Y6, all practices had implemented FIT testing, mirroring the larger trend in the United States..$^{22}$ Similarly, only a few practices had access to mobile mammography in the early years, and of those, not all utilized it regularly. By the end of Y6, 10 practices had a regular schedule with a

Table 4. Key Strategies to Promote Successful Implementation of Evidence-Based Interventions to Improve Breast, Cervical, and Colorectal Cancer Screenings

1. Share best practices with clinics similar to you and learn from them in return. Participating in a practice-based research network is a good way to do so, as is attending local/regional conferences and seminars.

2. Align quality improvement interventions with your practice's existing priorities and create office policies that link interventions to more general workflow adjustments and office procedures.

3. Establish policies and strategies to tackle cyclical barriers proactively, from staff turnover and inconsistent communication with specialists to data entry errors in the electronic health record.

4. Develop workflows and policies to assist patients in overcoming structural barriers and other social determinants of health that can affect preventive screenings, such as hosting a mobile mammography bus on-site at regular intervals and providing fecal immunochemical test kits.

5. Be aware of barriers reflective of current trends in the health system, from practice ownership changes to even ransomware attacks. These may necessitate a pause in implementation. 
mobile mammography bus and the remaining 2 practices had on-site imaging clinics.

The final key promoters involve linking interventions to wider practice workflows. One promoter was to align QI interventions with existing practice priorities. For many practices, the project goals of increasing colorectal and breast cancer screenings aligned with their patient-centered medical home requirements. Further, practices in larger medical groups or health systems had internal benchmarks to meet, and payers offered incentives for practices that met their targets. Interventions that supported practices in meeting such benchmarks, like patient education on FIT kits, were more likely to be successful. Likewise, another key promoter was new officewide policies. By linking cancer screening interventions to more general workflow adjustments and office procedures, uptake and sustained change were more likely. One new officewide policy introduced by practices was standing orders for preventive screenings. This saved time and made it easier for patients to complete screenings.

The difficulty with interventions is sustaining them after the completion of a QI project when project-specific supports and funding ends. This challenge is made harder by the stretched resources of safety-net primary care practices. The key promoters discussed here can serve as mechanisms to sustain improvements in a busy practice.

\section{Limitations}

This project was designed as part of the New York State Department of Health's larger cancer prevention strategy, not as research. ${ }^{9}$ As such, the focus group and interview question guide concentrated on QI, limiting the exploration of broader contextual factors. Further, changes in practice ownership and the small number of practices that continued to participate limited any examination of trends specific to practice type. Finally, it is possible that turnover in project personnel (practice facilitators and qualitative data analysts) over the 7 years has influenced the results. However, new personnel were trained in the project's methodology, and the principal investigator and QI consultant - both involved in the project from conception - reviewed each year's findings and the comprehensive final analysis. Lastly, the shift we observed in awareness of SDoH is also reflected in the literature. ${ }^{17,20,21}$

\section{CONCLUSIONS}

This 7-year quality improvement project revealed important promoters of and barriers to increasing cancer screening rates in safety-net practices at all levels, from the wider health system to individual patients. Overall, the key promoters for the safety-net practices were officewide changes to policy, aligning QI goals with practice priorities, and sharing successes across sites. Each of these promoters was made easier by the presence of a practice facilitator, a resource not all safety-net practices have. The key barriers are familiar to many primary care practices, including inaccurate electronic health record data entry, inconsistent communication with specialists, staff turnover, and social determinants of health. These require long-term efforts and resources to overcome, often a challenge for safety-net practices.

Beyond these key promoters and barriers, long-term data collection also highlighted the impact that such barriers can have on the accuracy of practice screening rates from year to year. ${ }^{14}$ For example, a barrier such as an EHR transition or EHR shutdown can affect a practice's screening rates, but when these rates are viewed over 6 years, the decrease is an outlier. Longitudinal data collection enables researchers and clinicians to identify more accurate screening rate trends and pinpoint such outliers. Further, this long-term focus highlighted the issue of cyclical barriers, which repeatedly impacted screening rates and thus cannot be termed outliers. For example, a practice could reduce transportation barriers by partnering with a mobile mammography unit to increase its breast cancer screening rates. However, addressing barriers like staff turnover and inconsistent communication with specialists did not prevent those problems from returning. Understanding such barriers is crucial, as cyclical barriers at all levels combine to reduce the accuracy of screening rates data, increasing the likelihood that underserved patients may fall through the cracks.

\section{Patient-Friendly Recap}

- Authors identified barriers to and promoters of efforts to increase cancer screening among primary care practices.

- Health system barriers included cybersecurity issues, retrieving test results from specialty practices. Practice barriers included personnel turnover, data entry errors in patient records.

- Practices changed from the thinking that patients are uncooperative to an awareness of challenges patients may face. Working with patients to overcome barriers like lack of transportation - as by mobile mammography or FIT kits - increased screening rates.

- Quality improvement strategies facilitated increases in screening but require time, resources, and staff. Aligning interventions with existing practice workflows can help to sustain gains. 


\section{Acknowledgments}

Beyond funding, this project "took a village" to accomplish. We owe our deepest gratitude to the primary care practices and their teams that participated over the past 7 years, and are indebted to the physicians, advanced practice providers, nurses, and practice staff at each site. We also have a large team of past and present project managers and practice facilitators that tirelessly worked with practices to create opportunities for improving the quality of care for underserved patients. Several community collaborators, notably including the American Cancer Society (Rochester office), provided educational materials and development opportunities. We are extremely grateful to our collaborators at the New York State Department of Health who recognized the value of these efforts and were committed to finding practice-based solutions to increase preventive cancer screening for underserved communities.

\section{Author Contributions}

Study design: Brady, Tumiel-Berhalter, Schad, Morley. Data acquisition or analysis: all authors. Manuscript drafting: Brady, Tumiel-Berhalter, Schad, Bentham, Morley. Critical revision: all authors.

\section{Conflicts of Interest}

None.

\section{Funding Sources}

This publication was supported by cooperative agreements NU58DP6102, NU58DP006309, U58DP002029, and U58DP003879, funded by the Centers for Disease Control and Prevention (CDC). Its contents are solely the responsibility of the authors and do not necessarily represent the official views of the CDC or the Department of Health and Human Services, Health Research, Inc., or the New York State Department of Health.

\section{References}

1. Griswold KS, Pottie K, Kim I, Kim W, Lin L. Strengthening effective preventive services for refugee populations: toward communities of solution. Public Health Rev. 2018;39:3. CrossRef

2. Goel MS, Wee CC, McCarthy EP, Davis RB, Ngo-Metzger Q, Phillips RS. Racial and ethnic disparities in cancer screening: the importance of foreign birth as a barrier to care. J Gen Intern Med. 2003;18:1028-35. CrossRef

3. Smith RA, Andrews KS, Brooks D, et al. Cancer screening in the United States, 2019: a review of current American Cancer Society guidelines and current issues in cancer screening. $C A$ Cancer J Clin. 2019;69:184-210. CrossRef

4. Siegel RL, Miller KD, Fuchs HE, Jemal A. Cancer statistics, 2021. CA Cancer J Clin. 2021;71:7-33. CrossRef

5. Adunlin G, Cyrus JW, Asare M, Sabik LM. Barriers and facilitators to breast and cervical cancer screening among immigrants in the United States. J Immigr Minor Health. 2019;21:606-58. CrossRef

6. Greiner KA, Engelman KK, Hall MA, Ellerbeck EF. Barriers to colorectal cancer screening in rural primary care. Prev Med. 2004;38:269-75. CrossRef

7. Browne AJ, Varcoe CM, Wong ST, et al. Closing the health equity gap: evidence-based strategies for primary health care organizations. Int J Equity Health. 2012;11:59. CrossRef

8. O'Malley AS, Beaton E, Yabroff KR, Abramson R, Mandelblatt J. Patient and provider barriers to colorectal cancer screening in the primary care safety-net. Prev Med. 2004;39:56-63. CrossRef
9. Mader EM, Fox CH, Epling JW, et al. A practice facilitation and academic detailing intervention can improve cancer screening rates in primary care safety net clinics. J Am Board Fam Med. 2016;29:533-42. CrossRef

10. Agency for Healthcare Research and Quality. Module 10. Academic detailing as a quality improvement tool. Last reviewed May 2013; accessed February 10, 2021. https://www. ahrq.gov/ncepcr/tools/pf-handbook/mod10.html

11. Dignan M, Shelton B, Slone SA, et al. Effectiveness of a primary care practice intervention for increasing colorectal cancer screening in Appalachian Kentucky. Prev Med. 2014;58:70-4. CrossRef

12. Agency for Healthcare Research and Quality. Module 1. Practice facilitation as a resource for practice improvement. Last reviewed May 2013; accessed February 10, 2021. https:// www.ahrq.gov/ncepcr/tools/pf-handbook/mod1.html

13. Weiner BJ, Rohweder CL, Scott JE, et al. Using practice facilitation to increase rates of colorectal cancer screening in community health centers, North Carolina, 2012-2013: feasibility, facilitators, and barriers. Prev Chronic Dis. 2017;14:E66. CrossRef

14. Morley CP, Schad LA, Tumiel-Berhalter LM, Brady LA, et al. Improving cancer screening rates in primary care practices via practice facilitation and academic detailing: a multiPBRN quality improvement project. $J$ Patient Cent Res Rev. 2021;8:315-22.

15. Schad LA, Brady LA, Tumiel-Berhalter LM, et al. Impact of COVID-19 on screening rates for colorectal, breast, and cervical cancer: practice feedback from a quality improvement project. J Patient Cent Res Rev. 2021;8:347-53.

16. Baxter NN, Sutradhar R, Li Q, et al. Do primary care provider strategies improve patient participation in colorectal cancer screening? Am J Gastroenterol. 2017;112:622-32. CrossRef

17. Koh HK, Oppenheimer SC, Massin-Short SB, Emmons KM, Geller AC, Viswanath K. Translating research evidence into practice to reduce health disparities: a social determinants approach. Am J Public Health. 2010;100 Suppl 1:S72-80. CrossRef

18. Easley J, Miedema B, Carroll JC, et al. Coordination of cancer care between family physicians and cancer specialists: importance of communication. Can Fam Physician. 2016;62:e608-15.

19. Spence N, Bhardwaj N, Paul DP 3rd, Coustasse A. Ransomware in healthcare facilities: a harbinger of the future? Perspect Health Inf Manag. 2018;(Summer):1-22.

20. Lebrun LA, Shi L, Chowdhury J, et al. Primary care and public health activities in select US health centers: documenting successes, barriers, and lessons learned. Am J Public Health. 2012;102 Suppl 3:S383-91. CrossRef

21. Rasanathan K, Montesinos EV, Matheson D, Etienne C, Evans T. Primary health care and the social determinants of health: essential and complementary approaches for reducing inequities in health. $J$ Epidemiol Community Health. 2011;65:656-60. CrossRef

22. Dougherty MK, Brenner AT, Crockett SD, et al. Evaluation of interventions intended to increase colorectal cancer screening rates in the United States: a systematic review and metaanalysis. JAMA Intern Med. 2018;178:1645-58. CrossRef

(C) 2021 Advocate Aurora Health, Inc. 